\title{
PENGEMBANGAN MODEL WISATA EDUKASI DI MUSEUM PENDIDIKAN NASIONAL
}

\author{
Tita Juwita ${ }^{(1)}$, Evi Novianti(2), Rusdin Tahir ${ }^{(3)}$, Awaludin Nugraha ${ }^{(4)}$ \\ (1) (2) (3) (4) Magister Pariwisata Berkelanjutan, Universitas Padjadjaran \\ tita18005@mail.unpad.ac.id,novianti.vi@gmail.com, rusdintahir@gmail.com, \\ awaludin.nugraha@unpad.ac.id
}

Submitted: 26 November 2019 Revised: 27 February 2020

Accepted :21 March 2020

\begin{abstract}
ABSTRAK
Museum Pendidikan Nasional merupakan museum yang mempunyai konsep modern dan kini telah banyak di kenal oleh para pengunjung khususnya di kalangan mahawasiswa dan peserta didik karena dari jumlah kunjungan yang datang mengunjungi Museum Pendidikan Nasional merupakan Mahasiswa dan Peserta Didik yang merupakan salah satu tuntutan dalam kurikulum. Dalam upaya pengembangan wisata edukasi di Museum Pendidikan Nasional masih terdapat beberapa kendala yaitu prosedur alur kepemanduan yang belum efektif karena sistem kepemanduan yang kurang sesuai dengan kebijakan pendidikan di museum, maka perlu adanya kebijakan-kebijakan pendidikan dan menerapkan sistem wisata edukasi dengan baik agar pelaksanaan program wisata edukasi di Museum Pendidikan Nasional berjalan dengan efektif agar dapat meningkatkan jumlah kunjungan. Penelitian ini bertujuan untuk mengetahui pengembangan wisata edukasi di Museum Pendidikan Nasional. Penelitian ini di lakukan untuk memberikan edukasi pada wisatawan khususnya pengunjung museum agar mengetahui seberapa besar penting nya wisata edukasi di Museum. Metode penelitian yang digunakan adalah metode kualitatif. Data yang diambil adalah data primer dan data skunder, dimana data primer diperoleh dari kuesioner dan wawancara kepada narasumber yang telah ditentukan yaitu wawancara dengan staf Museum Pendidikan Nasional mengenai prosedur wisata edukasi yang di terapkan oleh museum dan data skunder yang di peroleh dari Museum Pendidikan Nasional yaitu berupa jumlah kunjungan, sejarah museum, struktur organisasi dan visi-misi museum.
\end{abstract}

Kata Kunci: Museum Pendidikan, Pengembangan, Wisata Edukasi

\section{EDUCATION TOURISM DEVELOPMENT MODELS IN THE NATIONAL EDUCATION MUSEUM}

\section{ABSTRACT}

The National Education Museum is a museum that has a modern concept and is now widely known by visitors, especially in students and students because of the number of visits that come. the implementation system is not in accordance with the educational policies in the museum, it is necessary to have educational policies and tourism education system needs to be done well in order to run an educational tourism program in the National Education Museum running effectively in order to increase the number of visits. This research aims to study the development of tourism education in the National Education Museum. This research 
Tita Juwita, Evi Novianti, Rusdin Tahir, dan Awaludin Nugraha: Pengembangan Model

Wisata Edukasi di Museum Pendidikan Nasional

was conducted to provide education to special tourists who visit museums to be able to know the importance of tourism education in the Museum. The research method used is a qualitative method. The data taken are primary data and secondary data, while primary data obtained from questionnaires and interviews with predetermined sources, namely interviews with staff of the National Education Museum regarding tourist education procedures applied by the museum and secondary data obtained from the National Education Museum consists of number of visits, museum history, organizational structure and vision and mission of the museum.

Keywords: Development, Educational Museum, Educational Tourism

\section{PENDAHULUAN}

Museum identik dengan tempat yang membosankan karena di dalam museum hanya terdapat peninggalan yang bersejarah, pandangan tersebut harus di ubah bahwa museum merupakan tempat yang sangat menarik dan bisa menambah pengetahuan khususnya bagi para pengunjung. Beberapa museum yang ada khususnya yang berada di Kota Bandung kurang memiliki konsep yang menarik. aktifitas wisata bernuansa edukatif sudah begitu terlihat selama masa observasi di lapangan tetapi kurang nya minat para pengunjung untuk menikmati wisata di museum. Oleh karena itu perlu pengelolaan lebih dalam peranan wisata edukasi di museum khususnya Museum Pendidikan Nasional agar pengunjung yang datang tidak merasa bosan selama berwisata di museum.

\section{Edu-tourism atau Pariwisata}

Pendidikan dimaksudkan sebagai suatu program di mana peserta kegiatan wisata melakukan perjalanan wisata pada suatu tempat tertentu dalam suatu kelompok dengan tujuan utama mendapatkan pengalaman belajar secara langsung terkait dengan lokasi yang dikunjungi (Munir, 2010).

Wisata Edukasi atau edutourism adalah suatu program dimana wisatawan berkunjung ke suatu lokasi dengan tujuan utama memperoleh pengalaman pembelajaran secara langsung di objek wisata tersebut. (Rodger, 1998 :28 dalam Ratih, N : 2013).

Museum Pendidikan Nasional diharapkan keberadaanya mampu menjadi wahana pusat penelitian, dan juga menjadi sumber belajar dan pembelajaran, dan dapat meningkatkan wawasan dan kompetensi para pendidik dan tenaga kependidikan dalam meningkatakan mutu pendidikan, sekaligus menjadi tujuan wisata sejarah dan budaya di Jawa Barat dan Nasional. Museum Pendidikan Nasional diharapkan akan menjadi museum yang di jadikan wahana bagi para pengunjung yang bukan hanya melihat-lihat koleksi dari museum tetapi juga bisa melakukan suatu kegiatan dan mempunyai pengalaman. Karena pada dasarnya manusia tidak mempelajari masa lalu, melainkan masa depan. Museum Pendidikan Nasional Universitas Pendidikan Indonesia menyimpan dan merekam jejak sejarah khususnya dalam bidang pendidikan nasional melalui upaya konservasi, edukasi dan riset serta rekreasi yang "Leading and Outstanding.(Museum Pendidikan UPI.edu)

Koleksi yang berada di Museum Pendidikan Nasional merupakan koleksi yang mempunyai konsep sejarah dari Pendidikan yang ada di Indonesia. Museum Pendidikan Nasional ini menyajikan dinamika pemikiran kritis pendidikan nasional dan juga pendidikan guru di Indonesia. Museum ini juga diharapkan dapat mendukung program pemerintah yaitu "cinta museum" juga turut serta dalam menyukseskan Jawa Barat sebagai daerah tujuan wisata budaya dan pendidikan yang memiliki keunikan tersendiri.

Berdasarkan dari pengalaman dan hasil pengamatan dari penulis terdapat berbagai masalah. Museum Pendidikan Nasional yang baru berdiri beberapa tahun kurang di minati para pengunjung karena 
keberadaanya belum cukup dikenal di tingkat Nasional.

Museum yang sudah di anggap menjadi tempat yang kurang begitu menarik dan kurang mengakomodasi minat para pengunjung khususnya anak muda maka perlu di adakanyya program wisata edukasi agar bisa menarik para wisatawan khusus nya generasi muda. Museum juga harus mememiliki program dan kemasan yang modern dan mengikuti dengan perkembangan zaman. Sebagai destinasi wisata yang mempunyai konsep pendidikan, museum dibutuhkan model yang tepat dalam pengelolaanya. Penelitian ini di rancang untuk mengetahui Pengembangan model wisata edukasi yang sesuai dengan kondisi dan keadaan di museum pendidikan nasional.

Pada saat penulis melakukan observasi lapangan muncul masalah yang di temukan yaitu pertama, pelaksanaan alur wisata edukasi belum berjalan secara efektif karena pengorganisasian sistem alur wisata edukasi kurang terorganisir misalnya para pengunjung yang datang ditangani hanya dengan satu educator guide sementara para pengunjung yang datang biasanya para pengunjung rombongan dari sekolah atau universitas yang minimal 100 orang sekali berkunjung ke museum. dengan demikian Museum Pendidikan Nasional perlu menentukan kebijakan program wisata edukasi, metode wisata edukasi untuk lebih meningkatkan pelayan terhadap pengunjung yang datang dan alur yang lebih terarah agar proses wisata edukasi berjalan dengan baik dan para pengunjung mendapatkan ilmu pembelajaran yang juga menyenangkan.

Selain itu, educator guide yang berada di Museum Pendidikan Nasional adalah lulusan pendidikan yang tidak linear dengan tugas dan tanggung jawab nya sebagi educator guide hal tersebut bisa mengakibatkan proses wisata edukasi yang kurang berjalan dengan baik karena seorang educator guide khususnya harus mempunyai ilmu yang khusus dan mempunyai kompetensi dalam proses menyampaikan sejarah dan penjelasan mengenai koleksi yang berada di museum. Karena pengunjung yang datang mayoritas peserta didik maka para pengunjung harus mendapatkan ilmu pada saat datang ke museum dan bisa menghubungkan dengan kegiatan pembelajaran yang di dapat di sekolah.

Kegiatan Proses pembelajaran tidak hanya berlangsung di dalam kelas tetapi bisa di laksanakan di luar kelas agar para peserta didik bisa mengaitkan ilmu yang telah di dapat di kelas dengan pengetahuan yang di di dapata di luar kelas khususnya museum. Peran guru disini untuk memfasilitasi peserta didik dalam melaksanakan proses pembelajaran di luar kelas, karena di dalam kelas peserta didik hanya mendengarkan penjelasan dari seorang guru dan membaca buku sementara proses pembelajaran di luar kelas peserta didik bisa melihat secara langsung. Dalam hal tersebut maka dibutuhkan metode pembelajaran yang tepat di terapkan di museum.

Metode pembelajaran karyawisata merupakan metode atau suatu cara atau pembelajaran dimana pelaksanaan atau proses pembelajarannya dilaksanakan dengan menggunakan lingkungan luar yang mempunyai hubungan dengan isi materi pada materi pelajaran yang di ajarkan di sekolah secara langsung sehingga siswa dapat melihat dan mengalami langsung materi yang di sampaikan pada proses pembelajaran.

\section{TINJAUAN PUSTAKA}

Karyawista yaitu kegiatan wisata yang dilakukan oleh para peserta didik untuk melengkapi pengalaman belajar tertentu dan merupakan bagian dari kurikulum yang ada di Sekolah. Dengan karyawisata sebagai metode belajar, mengajar, peserta didik dibawah pengawasan bimbingan guru dengan mengunjungi tempat - tempat tertentu dengan maksud tujuan untuk belajar. Berbeda dengan tamasya dimana orang terutama pergi mencari liburan.

Metode pembelajaran yang cocok di laksanakan di museum yaitu metode karya wisata dan metode pembelajaran kontekstual. Metode Pembelajaran 
Kontekstual adalah sebuah proses pendidikan yang bertujuan untuk menolong para siswa melihat siswa melihat makna didalam materi akademik yang mereka pelajari dengan cara menghubungkan subyek-subyek akademik dengan konteks dalam kehidupan keseharian mereka.

Menurut (Johnson, E.B. 2007) Metode Pembelajaran Kontekstual adalah metode pembelajaran yang cocok untuk di berlakukan di museum. Pendekatan pembelajaran kontekstual merupakan pembelajaran yang mengaitkan antara materi yang di pelajari di kehidupan nyata. (Komalasari : 2014 dalam Maesari N : 2019)

Fasilitas umum yang dimiliki Museum Pendidikan juga belum mempunyai alur wisata yang terstruktur dan tidak ada nya kordinasi antara tour leader museum dengan guru sehingga tidak ada nya kesinambungan antara materi yang telah di terapkan di sekolah dan penjelasan yang ada di museum. Maka dari itu perlu adanya kordinasi yang berkesinambungan agar kegiatan pembelajaran yang ada di museum berjalan sesuai dengan konteks pembelajaran Konstekstual dan proses pembelajaran yang sangat menyenangkan sehingga meningkatkan minat para peserta didik dalam proses pembelajaran. Apabila tidak adanya kordinasi dengan metode pembelajaran yang sesuai tetapi menyenangkan maka akan menghambat program kegiatan wisata edukasi. Selain itu Manajemen sumber daya manusia yang ada di Museum Pendidikan Nasional yang kurang berkualitas di sebabkan para pegawai yang ada di Museum sebagian besar tidak memiliki kompetensi di bidang nya dan latar belakang pendidikan yang tidak sesuai sehingga tidak memahami tugas dan tanggung jawabnya. Hal tersebut mengakibatkan banyaknya komplen yang diterima karena sistem manajemen yang kurang bagus.

Pelaksanaan wisata edukasi di Museum Pendidikan Nasional harus menjadi museum yang menarik untuk para pengunjung khususnya peserta didik yang datang ke museum akan merasakan sistem pembelajaran yang menyenangkan melakui pengembangan wisata edukasi. Hal tersesbut akan menjadi kesan yang baik bagi para peserta didik sehingga meningkatkan daya tarik pengunjung untuk berwisata kembali khususnya wisata edukasi. Wisata edukasi apabila dilaksanakan dengan baik maka perlu adanya pengembangan agar meningkatkan minat para pengunjung untuk datang ke museum dan menjadikan Museum Pendidikan Nasional sehingga bisa dinikmati oleh para peserta didik di masa yang akan datang dan seterusnya.

\section{METODE}

Berdasarkan tahap pengumpulan data penelitian ini dimulai dari studi kepustakaan, lalu dilanjutkan dengan observasi juga wawancara dengan responden atau informan museum yaitu staf Museum Pendidikan Nasional : Kepala UPT Museum, Manajer Operasional dan Educator Guide. Dari hasil perpustakaan-perpustakaan dan lembagalembaga yaitu berupa buku, Jurnal, Laporan penelitian, surat kabar, laporan resmi, dan peraturan-peraturan sedangkan sumber visual berupa foto. Berikut juga dari sumber internet. tersebut diperoleh data yang berkaitan dengan profil Museum Pendidikan Nasional, Sejarah Berdirinya Museum Pendidikan Nasional, latar belakang dan perkembangan Museum Pendidikan Nasional menjadi objek wisata edukasi, kebijakan Pendidikan Museum Pendidikan Nasional.

Pada tahap observasi deskriptif, peneliti meneliti dan mengamati kegiatan wisata edukasi yang di laksanakan di Museum Pendidikan Nasional, lalu melakukan deskripsi terhadap semua yang dilihat, didengar, dan dirasakan. Selanjutnya hasil observasi pada tahap penelitian ini dapat disimpulkan dalam keadaan yang belum tertata. Kemudian pada tahap terakhir, yaitu tahap observasi terseleksi, dilakukan observasi yang lebih rinci terhadap aspek tertentu yang ditemukan dari hasil observasi terfokus. Kesimpulan dari tahap terakhir ini sudah dapat menemukan karakteristik, persamaan dan perbedaan antarkategori, serta 
menemukan hubungan antara satu kategori dengan kategori lainnya. Waktu pelaksanaan teknik observasi dilakukan dalam dua tahap, yaitu tahap pertama tanggal 18 September 2019 dan tahap selanjutnya tanggal 15 Oktober 2019.

Data yang diperoleh dalam penelitian kualitatif bersifat kualitatis, yaitu data berbentuk pernyataan-pernyataan sehingga analisisnya menggunakan metode analisis kualitatif interpretatif. Menurut Ratna (2010) (dalam nugraha 2019) metode ini merupakan metode kualitatif dengan menekankan pada aspek hermeneutika dan verstehen. Hermeneutika berarti menafsirkan. Penafsiran data dilakukan terhadap dua aspek, yaitu (1) aspek bahasa, dengan mempertimbangkan hubungan bagian dengan keseluruhan ucapan, dan (2) aspek psikologis, dengan cara menggali makna tersembunyi sang penutur. Analisis data dilakukan tidak lama setelah dimulainya proses pengumpulan data hingga selesainya pengumpulan data, lalu dilanjutkan sampai tersusunnya laporan penelitian Kegiatan analisis ketiga adalah penarikan kesimpulan dan verifikasi (Nugraha, 2019).

\section{HASIL DAN PEMBAHASAN}

\section{Hasil Penelitian}

Berdasarkan hasil dari penelitian ini adalah wisata edukasi di Museum Pendidikan Nasional belum berjalan dengan baik, dari segi konsep manajemen strategi, konsep museum, museum sebagai sarana pendidikan, atraksi, staf museum, alur kunjungan yang yang telah diterapkan dan manajemen pendidikan. Oleh karena itu Pengembangan model wisata edukasi sangat penting dilaksanakan dengan baik agar Museum Pendidikan Nasional dapat menjadi pusat pembelajaran di luar sekolah yang menarik para pengunjung untuk melakukan wisata edukasi.

Suatu objek wisata menjadi destinasi wisata yang selalu menarik maka perlu di kembangkan sehingga potensi yang ada dapat di gali sehingga pendapatan daerah nya dapat meningkatkan pertumbuhan ekonomi warganya.pengembangan sangat di perlukan agar destinasi wisata dapat menjadi lebih besar dan maju.

(Hadi, Wisnu: 2018)

Pengembangan model wisata edukasi di Museum Pendidikan Nasional sangat perlu dilaksanakan untuk meningkatkan kualitas museum dalam mempertahankan jumlah minat pengunjung dan bahkan meningkatkan pengunjung dari setiap tahun nya. Wisata edukasi merupakan konsep wisata yang paling sesuai untuk diterapkan di Museum Pendidikan Nasional, karena jumlah pengunjung yang mayoritas adalah peserta didik, fungsi utama dari museum merupakan sebagai edukasi.

Hasil penelitian ini menunjukkan bahwa tingkat kunjungan ke Museum Pendidikan Nasional di padati pengunjung pada saat ada kunjungan dari suatu sekolah atau wisatawan grup yang berjumlah ratusan yang datang secara bersamaan. Hal tersebut menunjukan bahwa museum Pendidikan Nasional merupakan destinasi wisata edukasi yang mayoritas di kunjungi oleh para peserta didik.

\section{Grafik 1-4 Data kunjungan Museum Pendidikan Nasional 4 tahun terakhir \\ Data Grafik : 1}

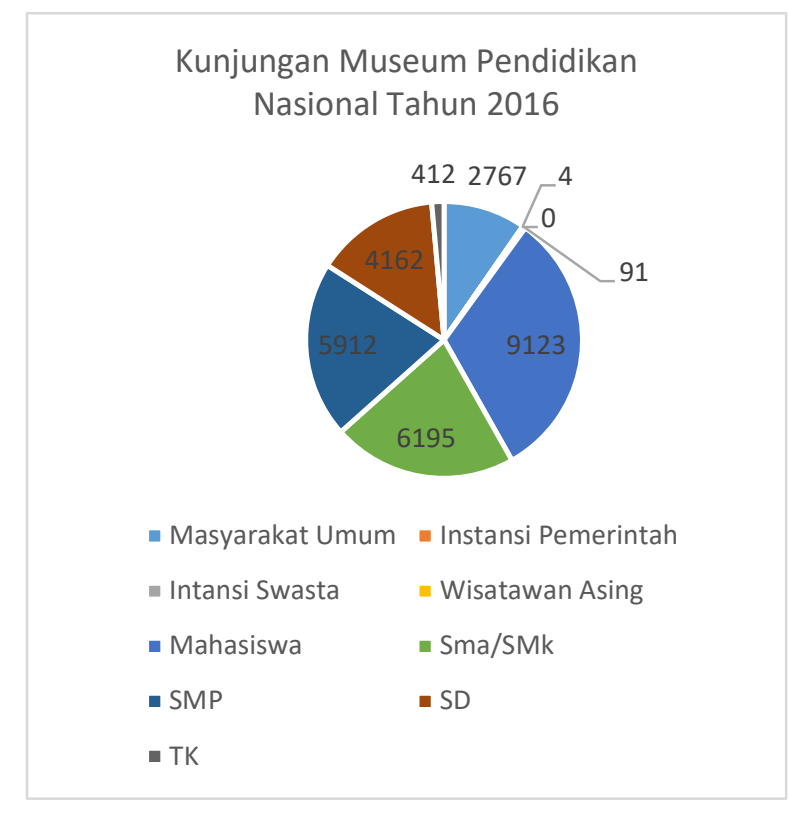

Data Grafik : 2 
Tita Juwita, Evi Novianti, Rusdin Tahir, dan Awaludin Nugraha: Pengembangan Model Wisata Edukasi di Museum Pendidikan Nasional

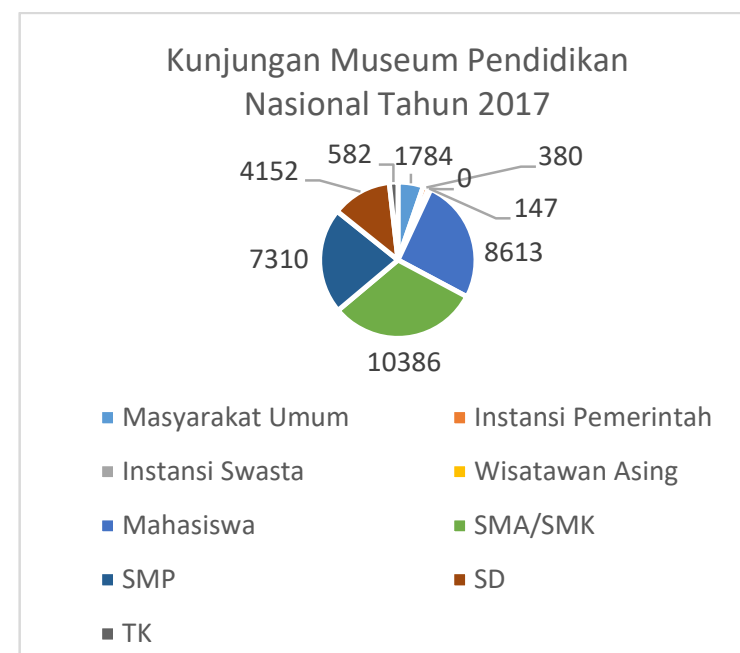

Data Grafik : 3

Data Kunjungan Museum Pendidikan Nasional Tahun 2018

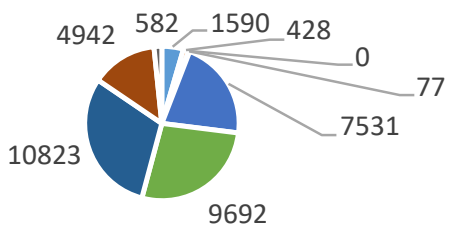

- Masyarakat Umum = Instansi Pemerintah

- Instansi Swasta Wisatawan Asing

- Mahasiswa $\quad$ SMA/SMK

- SMP $\quad$ SD

- TK

Data Grafik : 4

Data Kunjungan Museum Pendidikan

Nasional Tahun 2019 bulan (JanuariAgustus)

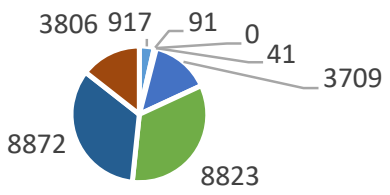

- Masyarakat Umum Instansi Pemerintah

- Instansi Swasta $\quad$ Wisatawan Asing

- Mahasiswa - SMA/SMK

- SMP $\quad$ SD

- TK

Sumber Data: Museum Pendidikan Nasional 2019

Dari data grafik diatas diberi kesimpulan bahwa jumlah pengunjung Museum Pendidikan Nasional selalu ada peningkatan setiap tahunnya dan pengunjungan didominasi oleh Mahasiswa dan Peserta didik, sementara yang mempunyai jumlah paling tinggi adalah peserta SMA/ SMK. Pengunjung peserta didik yang mengunjungi museum adalah pengunjung grup yang sudah ditetapkan oleh program pendidikan di sekolah.

Wisata edukasi di Museum Pendidikan Nasional perlu untuk diterapkan yang sesuai dengan beberapa konsep dan kebijakan pendidikan. Mulai dari metode pembelajaran, kebijakan mengelola edukasi, sumber belajar, program wisata edukasi „museum sebagai sarana pendidikan mempunyai tiga langkah penting, yaitu penerapan kebijakan pendidikan museum.

\section{Pembahasan}

Edukasi atau di sebut dengan pendidikn merupakan segala upaya yang di rencanakan untuk mempengaruhi orang lain baik individu, kelompok atau masyarakat sehingga mereka melakukan apa yang di harapkan oleh pelaku Pendidikan (Notoadmojo, 2003 dalam Rahmat P : 2018)

Jenis-jenis wisata edukasi

- Wisata edukas science/ ilmu pengetahuan

- Wisata edukasi sport

- Wisata edukasi culture

- Wisata edukasi agro bisnis

(Purnawan : 2012 dalam Prasetyo : 2019)

Museum perlu memiliki kebijakan untuk menentukan edukasi di museum. Kebijakan tersebut perlu mempertimbangkan hubungan yang sesuai antara edukasi yang relevan dengan koleksi, kebijakan edukasi yang mendorong kesadaran akan warisan budaya, kebijakan mengembangkan kemampuan pengelola edukasi dan kebijakan edukasi yang dapat melibatkan masyarakat setempat (Zahir, Widadi 2010). Dengan demikian kebijakan edukasi museum yang ideal dapat dikelompokan menjadi 6 kebijakan edukasi yaitu : 
Tita Juwita, Evi Novianti, Rusdin Tahir, dan Awaludin Nugraha: Pengembangan Model

Wisata Edukasi di Museum Pendidikan Nasional

\section{a. Kebijakan Edukasi dan Koleksi}

Dalam menentukan kebijakan edukasi perlu mempertimbangkan hubungan antara edukasi dengan

koleksi. Museum Pendidikan Nasional memiliki koleksi dengan beberapa konsep koleksi yang termasuk pada pariwisata 4.0. salah satu koleksi museum nya adalah : yang pertama yaitu display yang berbentuk elektronik yang berupa tambahan data dari diorama mengenai deskripsi informasi perkembangan Pendidikan yang ada di Indonesia dan kebudayaan pada zaman prasejarah melalui foto digital elektronik dan konvensional serta dilengkapi dengan video mengenai kehidupan masyarakat tradisional di seluruh Nusantara. Komputer yang dilengkapi komputer interaktif yang berisi kuis,/games atau permainan yang mempunyai hubungan dengan materi. Yang kedua Museum juga memamerkan beberapa koleksi buku, alat tulis, ijazah, materi pelajaran atau kurikulum dan alat belajar lainnya dari yang paling klasik hingga yang paling modern. Selain itu disediakan juga pula ruang pendukung seperti ruang perpustakaan, ruang riset, dan ruang pamer temporer. Yang ketiga sejarah pendidikan guru dan sejarah guru dari zaman kolonial hingga zaman Reformasi. Selanjutnya menyediakan dinding puzzle balok berbentuk segitiga yang dapat disusun menjadi gambar pembelajaran di sekolah guru pada masa kolonial, baik di kweekschool, normalschool, hogere kweekschool, Hollands Inlandsche Kweekschool (HIK) menggantikan HKS, Hollands Chinese Kweekschool.

Museum Pendidikan Harus mempunyai sistem yang lebih terarah untuk wisata edukasi di Museum Pendidikan Nasional salah satu nya Museum Pendidikan Nasional harus menentukan kebijakan edukasi bagi setiap koleksi yang dipamerkan harus disertai keterangan koleksi. Kebijakan tersebut dapat dibuat secara tertulis sebagai acuan petugas tata pemeran dan termasuk juga karyawan yang bertugas sebagai pemandu. Hal yang terpenting disampaikan kepada pengunjung mengapa beberapa konsep koleksi museum tersebut itu diperlukan dalam memahami pembelajaran yang ada di museum.

Permasalahan yang terjadi di museum pendidikan bahwa educator guide yang memandu para wisatawan yang datang kurang memahami konsep dari beberapa sejarah dari koleksi museum karena terbatasnya educator guide yang ada di Museum dan pendidikan dari seorang educator guide yang tidak linear dengan tugas nya sebagai seorang educator guide.

b. Kebijakan Mengelola Wisata Edukasi

Sumber daya manusia salah satu yang ikut menentukan keberhasilan museum dalam menyampaikan edukasi. Museum Pendidikan Nasional memiliki keterbatasan karyawan yang mengerti tentang pengetahuan museum dan sejarah dari konsep-konsep koleksi museum. Sebagian besar karyawan yang ada di Museum Pendidikan Nasional tidak sesuai kompetensi pendidikannya dengan tugas dan tanggung jawab pekerjaan nya, selain itu educator guide disini latar pendidikan nya adalah Bahasa Inggris sementara seorang tour guide harusnya memahami konsep museum dan sejarah dari koleksi museum yang ada di Museum Pendidikan Nasional.

\section{c. Metode Pembelajaran di Museum Pendidikan Nasional}

Hasil pengamatan peneliti pada saat di lapangan, Museum Pendidikan Nasional hanya menggunakan satu metode pembelajaran yaitu metode discovery learning. Metode pembelajaran yang belum di terapkan di Museum Pendidikan Nasional yaitu metode pembelajaran Contextual Teaching Learning (CTL) dpat di terapkan di Museum.

Metode Pembelajaran kontekstual (CTL) merupakan konsep belajar yang membantu guru dalam mengaitkan antara materi yang telah diajarkan di dalam kelas dengan situasi yang ada dunia nyata. Selain itu mendorong siswa membuat hubungan antara materi yang 
telah di terima pada saat pembelajaran di dalam kelas, dan dalam kehidupan mereka sehari-hari, dengan melibatkan tujuh komponen utama yaitu pembelajaran efektif, yaitu: konstruktivisme (Contructivism), bertanya (Questioning), menemukan (Inquiri), masyarakat belajar (Learning Community), pemodelan (Modelling), refleksi (reflection), dan penilaian yang sebenarnya (Authentic Assesment). (Johnson, E.B, 2007)

Menurut penjelasan berikut maka metode pembelajaran Contextual Teaching Learning cocok diterapkan di Museum khususnya Museum Pendidikan Nasional Pembelajaran kontekstual merupakan pembelajaran yang sangat cocok digunakan di museum. Pendekatan kontekstual dalam proses pembelajaran di Museum dalam merubah proses pembalajaran yang ideal di Museum, karena para peserta didik juga Mahasiswa dalam mengaplikasikan pembelajaran yang telah di miliki sebelumnya di kaitkan dengan dunia nyata. Sehingga informasi yang mereka terima dapat di sesuaikan dengan tujuan pembelajaran.

Selanjutnya adalah metode pembelajaran karya wisata, metode karya wisata ini juga cocok untuk diterapkan di Museum. Metode karya wisata merupakan kunjungan ke luar kelas dalam rangka belajar. Metode karya wisata juga dapat di artikan sebagai kegiatan perjalanan atau kunjungan lapangan. Agar pembelajaran yang telah diterapkan di kelas dapat di aplikasikan kedunia nyata maka metode karya wisata ini sangat baik untuk menghasilkan proses pembelajaran yang maksimal.

\section{d. Museum Sebagai Sumber Belajar Sejarah Pendidikan}

Proses pembelajaran di Museum Pendidikan Nasional bertujuan untuk menentukan teori belajar di museum, sehingga dapat dipahami secara komprehensif edukasi apa yang akan disampaikan kepada pengunjung dan bagaimana menyampaikan edukasi tersebut kepada pengunjung.

Wisata Edukasi di Museum Pendidikan Nasional secara teori merupakan pengetahuan dari pemaknaan proses pembelajaran sejarah khususnya sejarah pendidikan yang ada di Indonesia.

Proses pembelajaran dilakukan melalui penyajian koleksi sejarah pendidikan. Selanjutnya Educator guide menjelaskan pengetahuan dan makna yang terdapat pada koleksi secara langsung kepada pengunjung sambil berkeliling melihatlihat koleksi. Museum ini memberikan informasi koleksi secara tertulis dalam bentuk keterangan koleksi. Tujuannya untuk penyampaian hasil interpretasi museum terhadap koleksi mengenai makna, pengetahuan, proses pembuatan, sejarah, budaya.

\section{e. Didaktik Pemanduan dan Dialog}

Pelayanan pemanduan yang diberikan oleh seorang Educator Guide di Museum Pendidikan Nasional kepada wisatawan mengenai Pendidikam zaman prasejarah, Pendidikan brrbasis agama seperti Hindu, Buddha, Islam, selanjutnya zaman kolonial, pendidikan zaman pergerakan, zaman Jepang, zaman Awal kemerdekaan.

Pendidikan Di jawa barat, tokoh tokoh Pendidikan Nasional, selanjutnya bagian sejarah dewi sartika, Sejarah berdirinya Universitas Pendidikan Indonesia dari PTPG hingga Universitas pendidikan Indonesia, Rektor-Rektor Universitas Pendidikan Indonesia dan Universitas Pendidikan Indonesia di masa depan dan terakhir di museum wirayudha bhatara.

Permasalahan yang telah ditemukan, berdasarkan pengamatan dilapangan setiap pengunjung di Museum Pendidikan Nasional dipandu oleh satu orang educator guide sementara pengunjung yang sering datang ke museum adalah mahasiswa dan siswa SMK/SMA SMP dan SD yang merupakan kunjungan group atau rombongan yang sekali kedatangannya adalah minimal 100 orang, sehingga kegiatan pemanduan dengan demikian proses pemanduan tergantung dari petugas bukan kebutuhan 
Tita Juwita, Evi Novianti, Rusdin Tahir, dan Awaludin Nugraha: Pengembangan Model

Wisata Edukasi di Museum Pendidikan Nasional

pengunjung. Pemandu seharusnya melakukan upaya agar pengunjung bisa berdialog terhadap pengunjung. Pengungjung koleksi kain batik tentunnya sudah memilki pengalaman sendiri dan petugas pemandu membantu pengunjung untuk menemukan makna untuk pengunjung itu sendiri

\section{f. Program Wisata Edukasi Museum}

Selama ini Museum Pendidikan Nasional telah menjalankan program wisata edukasi. Dalam pembahasan program wisata edukasi ini dapat menganalisis program kegiatan wisata edukasi di museum adalah untuk mengetahui tujuan, cara pelaksanaan dan sasaran dari wisata edukasi yang diharapkan. Langkah pertama yang dilakukan dalam program pembelajaran wisata edukasi tersebut pengunjung khususnya pengunjung peserta didik/ mahasiswa akan di berikan selembar kertas yang berbentuk LKS, di dalam LKS tersebut siswa di tuntut untuk mengisi LKS selama pemanduan berlangsung sehingga kegiatan wisata edukasi berlangsung berjalan dengan efektif karena siswa harus berkosentrasi dalam proses wisata edukasi berlangsung. Hasil dari perolehan jawaban para siswa secara keseluruhan akan saling terkait dan berhubungan sebagai sebuah program wisata edukasi di museum. Setelah itu hasil LKS dan Kunci Jawaban tersebut di berikan pada guru untuk di jadikan bahan evaluasi guru pada saat di sekolah.

\section{KESIMPULAN}

Berdasarkan hasil penelitian dapat di simpulkan hal - hal sebagai berikut. Dalam penelitian ini wisata edukasi di Museum Pendidikan Nasional kurang terlaksana dengan baik karena museum tidak menerapkan kebijakan Pendidikan yang seharusnya ada dalam pelaksaan wisata edukasi di museum. Dengan menerapkan kebijakan Pendidikan dalam pelaksanaan wisata edukasi di museum dapat meningkatkan minat pengunjung untuk melakukan kegiatan pembelajaran yang mempunyai konsep wisata edukasi.penunjung yang mayoritas adalah mahasiswa dan peserta didik dapat mendapatkan ilmu yang bermanfaat pada saat datang ke museum.

\section{DAFTAR PUSTAKA}

Hadi, Wisnu. 2018. "Analisa Terhadap Pengembangangan Obyek Wisata Di Mata Mahasiswa Luar Jawa Sebagai Wisatawan Di Daerah Istimewa Yogyakarta" Journal Of Indonesian Tourism Hospitality and Recreation. Volume 1 Nomor 2. Jurusan Perhotelan Universitas Bina Sarana Informatika.

Johnson, E.B. 2007. Contextual Teaching and Learning : menjadikan kegiatan belajar mengajar mengasyikan dan bermakna. Bandung : Mizan Learning Center.

Maesari, Nadhia dan Dadang Suganda, C. U. R. 2019."Pengembangan Wisata Edukasi Berkelanjutan Di Museum Geologi" : Journal of Tourism, Travel and Hospitality. Bandung. Magister Pariwisata Berkelanjutan. Universitas Padjajaran

Nugraha, Awaludin. 2019. Pariwisata Berkelanjutan Berbasis Kearifan Lokal (Studi Kasus Masyarakat Kampung Naga Kabupaten Tasikmalaya Provinsi Jawa Barat). Sekolah Pascasarjana Universitas Gadjah Mada Yogyakarta.

Prasetyo, Temoteus dan Hadi Atmoko. 2019. "Pengembangan Wisata Sebagai Daya Tarik Situs Rumah Sandi Di Perbukitan Menoreh Kulon Progo". Journal Of Indonesian Tourism Hospitality and Recreation. Volume 2, No 1. Akademi Pariwisata Yogyakarta

Priyanto, Rahmat dan Didin Syarifuddin, Sopa Martina. 2018. "Perancangan Model Wisata Edukasi di Objek Wisata Kampung Tulip". Jurnnal Abdimas BSI Hal 32-38. STP Ars Internasional

Ratih, N R, dan Beta S, Nurarchmad S.2013" Perencanaan wisata edukasi lingkungan hidup di Batu dengan penerapan material alami" Jurnal Mahasiswa 
Tita Juwita, Evi Novianti, Rusdin Tahir, dan Awaludin Nugraha: Pengembangan Model Wisata Edukasi di Museum Pendidikan Nasional

Jurusan Arsitektur Volume 1 (No 1). Fakultas Teknik Universitas Brawijaya.

Zahir, Widadi. 2010. "Peran Edukasi Museum" Studi Kasus Museum Batik di Pekalongan". Universitas Indonesia. Depok

\section{SUMBER INTERNET}

pada tanggal 11-juni-2019

http://museumpendidikannasional.upi.edu/

DR. MUNIR, M.IT diakses pada tanggal 12Juli-2019

http://munir.staf.upi.edu/2010/10/11/educatio nal-tourism-pariwisata-pendidikan/

Metode karya wisata. diakses pada tanggal 19 November 201916.07

https://idtesis.com/metode-pembelajaran-

karyawisata/

Tim Pengabdian Masyarakat STP ARS Internasional dan AKPAR BSI Bandung. diakses pada tanggal 12- Juli-2019

https://www.academia.edu/34895269/BUKU PANDUAN_WISATA_EDUKASI.pdf 